\title{
Explosive Substances and Their Applications: An Overview
}

\author{
Hansruedi Bircher*
}

\begin{abstract}
A systematic overview about the different types of energetic material is given. The chemical composition, the reaction behavior, and the initiation mechanisms of explosives are discussed.
\end{abstract}

Keywords: Explosives · Propellants · Pyrotechnics $\cdot$ Reactions

\section{Introduction}

The term 'explosive material' defines a substance or a mixture of substances capable of producing gas at such temperature and pressure by chemical reaction as to cause damage to the surroundings. This also includes pyrotechnic substances even though they may not evolve gases as they react [1]. Similar definitions can be found in corresponding international standards [2] as well as in national laws and regulations, whereas only those substances that are produced with the intention to be used as explosive material fall under these laws. Chemical by-products or intermediate products, such as peroxides, explosive clouds, or aerosols formed by a fuel and the oxygen of air are sometimes excluded, if they are not produced to cause a damaging effect. This is also the case for fertilizers containing ammonium nitrate, which can have the potential to be used as a component in explosive material [3].

From a chemical point of view, most explosives are substances or mixtures thereof, which are capable of releasing large amounts of hot gaseous products over a short period of time when they undergo the intended chemical reactions. Almost all re-

${ }^{*}$ Correspondence: Dr. H. Bircher armasuisse

Science and Technology

Feuerwerkerstrasse 39

$\mathrm{CH}-3602$ Thun

Tel.: +41332283003

Fax: +4133228 3039

E-Mail: hansruedi.bircher@armasuisse.ch actions of explosive substances proceed exothermally. This means that explosives need to have chemical groups in their molecules that increase their heats of formation and produce gaseous products upon reaction. This type of chemical groups is called explosophorics. The most famous explosophoric groups are based on nitrogen and oxygen, such as the classical nitro, nitrate, nitrate ester, nitramine, azide, and azido groups. Also well known are perchlorates and chlorates. Due to these explosophoric groups, the oxygen needed for the conversion of explosives into their gaseous reaction products, such as $\mathrm{NO}_{\mathrm{x}}$, $\mathrm{CO}_{2}, \mathrm{CO}$, and $\mathrm{H}_{2} \mathrm{O}$, is available within the corresponding molecules. This prerequisite becomes more and more important, the faster a chemical reaction proceeds, because the diffusion process in the air is no longer efficient enough to deliver sufficient amounts of oxygen for the chemical conversion. The nitrogen of explosophoric groups strongly supports the gas production rate, as does the chlorine in chlorates and perchlorates. So, the oxygen balance, i.e. the percentage of oxygen chemically bound in a molecule to oxidize it completely (Eqn. 1 ), as well as the nitrogen content of a molecule are the key parameters for the identification of explosive substances and their mixtures (Table) [4][5].

Many books on explosives discuss either in their introduction or in detail the most important properties of well-known traditional explosives, such as glycerine trinitrate, nitrocellulose or trinitrotoluene [6-9]. Some of them also cover recent developments in the field [10-13]. For many applications however, traditional substances are still important and therefore are still being used in large quantities. Over the last decades the chemistry of explosives has made great progress [14]. High density $\left(>2.0 \mathrm{gcm}^{-3}\right)$ organic molecules with high energy contents were developed [15]. A whole series of new energetic plasticizers and synthetic polymers exists, which are the base for modern binder systems [16]. There are substances available with high nitrogen content for propulsion [17]. In the field of pyrotechnics, where almost exclusively inorganic substances are used to generate the intended effects, new reducing agents, mostly introduced as fine grained metal powders, and new oxidizers are under close examination [18]. As the most recent development in the field of explosive materials, the investigations using nano particles and the application of sol-gel chemistry have to be mentioned [19]. In this paper an overview is given of which explosive substances are used for different applications and what the future trends and tendencies are. Before going into more detail, different reaction types and their initiation pathways are introduced.

\section{Explosives and Reaction Types}

Four different reaction types are distinguished according to velocity. The slowest reaction type is the ageing reaction, which can proceed at ambient temperatures over the timeframe of years. Ageing reactions result in energy loss, change of mechanical properties, and gas evolution. Several orders of magnitude faster is the burning reaction, which proceeds with linear burning velocities up to several meters per second. A conversion of an explosive by deflagration is again faster and reaches velocities of several hundred meters per second. And finally, the fastest reaction can be observed when explosives detonate. Detonation reac- 
Eqn. 1: Oxygen balance $(\mathrm{OB})$ for an explosive of type $\mathrm{C}_{x} \mathrm{H}_{\mathrm{y}} \mathrm{N}_{z} \mathrm{O}_{\mathrm{v}}$ and $\mathrm{w} * \mathrm{Al}$ to be oxidized completely to $\mathrm{H}_{2} \mathrm{O}, \mathrm{CO}_{2}$ and $\mathrm{Al}_{2} \mathrm{O}_{3}$.

$$
O B=100 * \frac{M W(O)}{M W(\operatorname{Expl})}\left(v-2 x-\frac{1}{2} y-\frac{3}{2} w\right)
$$

\section{MW: Molecular Weight}

Eqn. 2: Heat flow in explosive material

$$
\lambda \Delta^{2} T=\rho c_{p} \frac{d T}{d t}-\rho \sum_{i} Q_{i} \frac{d \varepsilon_{i}}{d t}
$$

$\lambda$ : thermal conductivity, $\Delta^{2}$ : Laplacian operator, T: temperature, $\rho$ : density, $c_{\mathrm{p}}$ : specific heat, t: time, $Q_{j}$ : heat of reaction i, $\varepsilon_{i}$ : progress of reaction $i$

Eqn. 3: Vieille equation for linear burning rate

$$
r=\frac{d x}{d t}=\Lambda p^{n}
$$

r: linear burning rate, A: calibration factor, $\mathrm{p}$ : pressure, $\mathrm{n}$ : burning rate index

Eqn. 4: Mass consumption by a burning reaction

$$
\frac{d m}{d t}-S(t) \rho r
$$

m: mass, t: time, $S$ : surface, $\rho$ : density, $r$ : linear burning rate

Eqn. 5: Critical energy for initiation of explosives by shock waves

$$
E_{c}=\frac{p^{2} t}{\rho_{0} U}
$$

\begin{tabular}{|c|c|c|c|}
\hline Substance & Oxygen Balance & Nitrogen Content & Explosive \\
\hline Silicon dioxide & $0.0 \%$ & $0.0 \%$ & no \\
\hline $\begin{array}{l}\text { 1,2,3-Propanetriol trinitrate } \\
\text { (Glycerine trinitrate) }\end{array}$ & $3.5 \%$ & $18.5 \%$ & yes \\
\hline $\begin{array}{l}\text { 1,3,5,7-Tetranitro- } \\
\text { 1,3,5,7-tetraazacyclooctane } \\
\text { (Octogen or HMX) }\end{array}$ & $-21.6 \%$ & $37.8 \%$ & yes \\
\hline 2,4,6-Trinitrotoluene & $-73.9 \%$ & $18.5 \%$ & yes \\
\hline $\begin{array}{l}\text { 2,4,6-Triamino- } \\
\text { 1,3,5-triazine (Melamine) }\end{array}$ & $-114.2 \%$ & $66.6 \%$ & no \\
\hline
\end{tabular}

Ec: critical energy, $p$ : shock wave pressure, t: shock impact time, $\rho_{0}$ : initial density of the explosive, U: shock wave velocity

Table. Oxygen balance and nitrogen content of different substances in view of their explosiveness.

tions proceed with several thousand meters per second.

\subsection{Ageing Reactions}

As already mentioned ageing reactions occur at ambient temperature and proceed very slowly for most common explosives. In many cases no obvious changes can be observed by visual inspection and also the degree of conversion remains very low. Nevertheless, self heating due to exothermal conversion and transition into a burning reaction occurs according to the heat-flow equation as a function of heat production, specific heat, thermal conductivity, and the dimension of an explosive charge (Eqn. 2) [4][20]. Such heat flows are measured at slightly higher temperatures $\left(40{ }^{\circ} \mathrm{C}-80{ }^{\circ} \mathrm{C}\right)$ by heat-flow calorimetry and then extrapolated back to ambient temperature using an appropriate kinetic model. Thereby either an Arrhenius approach based on an n-th order reaction [21] or a model free evaluation method is used, where for a temperature raise of $10{ }^{\circ} \mathrm{C}$ an increase of reaction rate by a certain factor is assumed. Whereas most aromatic and aliphatic nitro compounds show only negligible chemical degradation over long time periods, ageing reactions are a critical problem for nitrate esters.

The main factors for ageing reactions are temperature, humidity, and acid residues. Most nitrate esters need to be protected with a stabilizer, which is capable of catching free $\mathrm{NO}_{x}$ radicals originating from corresponding ageing reactions. Most of these stabilizers contain mono- or diphenylamine units, sometimes connected over a urea bridge. In the first step, these phenyl amino units are mainly converted to N-nitroso and 2-nitro or 4-nitro derivatives [22]. The comparison of the actual stabilizer content with the initial content gives a good indication about progress of ageing reactions. Also reducing agents of pyrotechnical redox systems, such as magnesium or titanium can be affected by ageing processes, especially if humidity is present. The conversion of magnesium to magnesium hydroxide under generation of hydrogen gas takes place quite easily. Such reactions can affect the functionality of corresponding pyrotechnic items fundamentally. A further important ageing reaction is the fissure of polymeric chains [23]. In the case of nitrocellulose, the glycosidic bond is broken and the linear chain is split into polymeric units of much lower molecular weight. The same ageing reaction can also be observed for other cellulose-based polymers, such as cellulose-acetate-butyrate or poly-esters, which are quite often used in binders systems of solid rocket propellants. Polymer chain fissures change the mechanical properties of corresponding charges and therefore also their ballistic behavior.

\subsection{Burning Reaction}

The burning reaction of an explosive starts if the temperature is raised above its ignition temperature. The burning process itself is a self-sustaining, exothermic redox reaction. Due to the heat, the corresponding hot gases, and the fine particles released in a first step, the reaction normally continues in the gas phase under emission of light. For the transfer of heat generated by such reactions, a conductive and a convective mechanism is distinguished. The conductive heat transfer mechanism is influenced by the same parameters as already described for the heat transfer of ageing reactions (Eqn. 2). When modeling such phenomena based on finite element simulations, the instant 
change of all material parameters behind the reaction zone has to be taken into account. The explosive charge itself burns layer by layer and the temperature within the charge decreases with distance to the reaction zone. The velocity of the linear burning reaction is given by the steady state of heat production and the efficiency of heat transfer to reach ignition temperature within the material. If the pressure around a charge rises and the hot gases have no possibility to escape, the heat transfer becomes more efficient and the burning rate increases. These phenomena is described in the law of Vieille (Eqn. 3), where A is a constant, depending on pressure units used, and $\mathrm{n}$ is the burning rate index, an experimentally determined parameter, which is characteristic for a certain explosive. Typically $\mathrm{n}$ varies between 0.3 and 1.0 [11]. If the burning surface area and the density is known, this simple relationship allows the mass of explosive consumed per unit time to be calculated (Eqn. 4).

Today thermo-chemical models are available to calculate gas production rate, reaction temperatures and by integration the pressure as function of time. As Eqn. 4 shows, the gas production rate and thereby the change of pressure as function of time can be controlled by the burning surface area.

The initial geometrical shape of a propellant grain or a solid rocket motor can be used to design the gas production rate in a more progressive or more digressive way. For example, a cylindrically shaped propellant grain shows a digressive burning characteristic, because its surface area decreases during the burning process. If the same grain contains seven cylindrical perforations, the surface area and the gas production rate will increase and the grain burns progressively [9].

The situation is completely different if the convective heat transfer mechanism is the main factor for heat transfer. Hot gases and glowing particles distribute heat by convection. This type of reaction is much harder to control, because it takes place between explosive particles or in porous material, where the surface area is normally unknown and the convection is hard to describe. If the energetic material is a fine powder, the surface area becomes very large and therefore the risk that the burning reaction turns into a deflagration or detonation is enhanced.

\subsection{Deflagration Reaction}

Deflagration is an intermediate reaction state between burning and detonation. As already mentioned convective burning of energetic material with a large surface area can develop into deflagration. The same is true for heavily confined explosive material. The linear velocity of the reaction achieves the magnitude of the material's sound speed. First shockwaves passing the material are generated. A deflagration reaction is physically unstable and therefore hard to control. Whether the reaction is accelerated further to supersonic velocities and so to a detonation, or the reaction decreases again to burning, depends strongly on the type of explosive, its surface area in this moment and its confinement. It can be observed quite often that the reaction of a deflagrating shell even stops, as soon as its casing has broken into parts and this way its confinement was released.

\subsection{Detonation Reaction}

The burning as well as the deflagration reaction is based on heat transfer. This is in contrast to the mechanism of a detonation, where the chemical reaction is triggered by a supersonic shock wave, traveling through the explosive material. For a stable detonation, the velocity of this shock wave is given by a steady state, where the energy consumed by shock wave attenuation can be compensated by energy from chemical conversion. In this case the shock wave velocity corresponds to the detonation velocity. The part of energy which is available to maintain the shock wave, depends strongly on the reaction rate of the explosive. As literature shows, only the reaction energy, which is released within $0.1 \mu$ s after the front of the shock wave has passed, contributes to the detonation velocity [24]. The reaction rate itself depends on the chemical homogeneity of the explosive. The reaction of a pure organic explosive takes place in this time frame. The more heterogeneous a high explosive composition is, the slower is the reaction rate and the more energy is lost to maintain shock wave velocity. This effect is obvious for some commercial or underwater explosives, which can have detonation velocities below $3000 \mathrm{~ms}^{-1}$ even at very high reaction energies. The sound velocity of a material depends on its density as does supersonic attenuation. So, the detonation velocity also depends on the density of the corresponding explosive. Therefore, explosives with high detonation velocities have not only to be chemically as homogeneous as possible, but also their densities and their reaction energies have to be optimized. The fastest detonation velocity measured so far is $9280 \mathrm{~ms}^{-1}$ [25].

\section{Initiation of Explosives}

A detonation reaction can be initiated by two different energy transfer mechanisms: In the case of deflagration-to-detonation-transition (DDT), a burning reaction is accelerated to a deflagration and by corresponding interference of shock waves further to a detonation. The main parame- ters responsible for the acceleration of the reaction are, among others, the energy released by the reaction and the rate of gas generation. These two parameters are directly related to the composition of the explosive and the chemical structure of its components. The chemical structure defines also the general tendency to undergo DDT. Nitrate esters with equalized or positive oxygen balance (Eqn. 1), such as glycerine trinitrate or pentaerythriol tetranitrate (PETN) are known to have this behavior. A large surface, related to the grain size of the material and its porosity (or density), further supports a burning or deflagrating explosive to run into a detonation. Finally the confinement of the material plays an important role. A heavy confinement prevents gases from a burning reaction from escaping. The pressure increases, this again accelerates the reaction up to a deflagration and from there into a detonation [24]. The influence of confinement on the DDT behavior can be shown with trinitrotoluene (TNT). If a pile of TNT grains is ignited with a matchstick, it burns slowly, with a sooty flame, until all TNT is consumed. If one heats up TNT in a heavy confined tube, the reaction will end up in a detonation. This is a typical behavior for a main charge explosive. A different behavior is necessary in ignition trains, where primary explosives in unconfined conditions must show a DDT characteristic. Therefore, primary explosives are dangerous and should not be handled without taking appropriate safety measures.

Another mechanism to initiate an explosive charge is based on the impact of a shock wave. For this type of initiation, known as shock-to-detonation-transition (SDT), a critical energy can be defined which describes the limit for initiation (Eqn. 5). This limit is a typical value for a specific explosive at a certain density [4]. Experimentally such critical energies can be determined with so-called gap tests, where the shock wave pressure for $50 \%$ initiation probability is determined by Bruceton statistics [26]. In contrast to the DDT mechanism, it is quite often observed that a shock wave impact on explosive material either results in a detonation or on the other hand in mechanical damage of a charge, without any visible traces of a chemical reaction. Apart from shock wave pressure, the time of pressure interaction on the explosive is an important factor. These interaction times are very short (sub $\mu$ s range) in the case of shock waves generated by detonations, but can be much longer in the case of large fragments. Further important parameters for SDT initiation are the density and the sound speed of the explosive material, whereas these two parameters are not independent. Low density charges are much easier to initiate by SDT compared to 


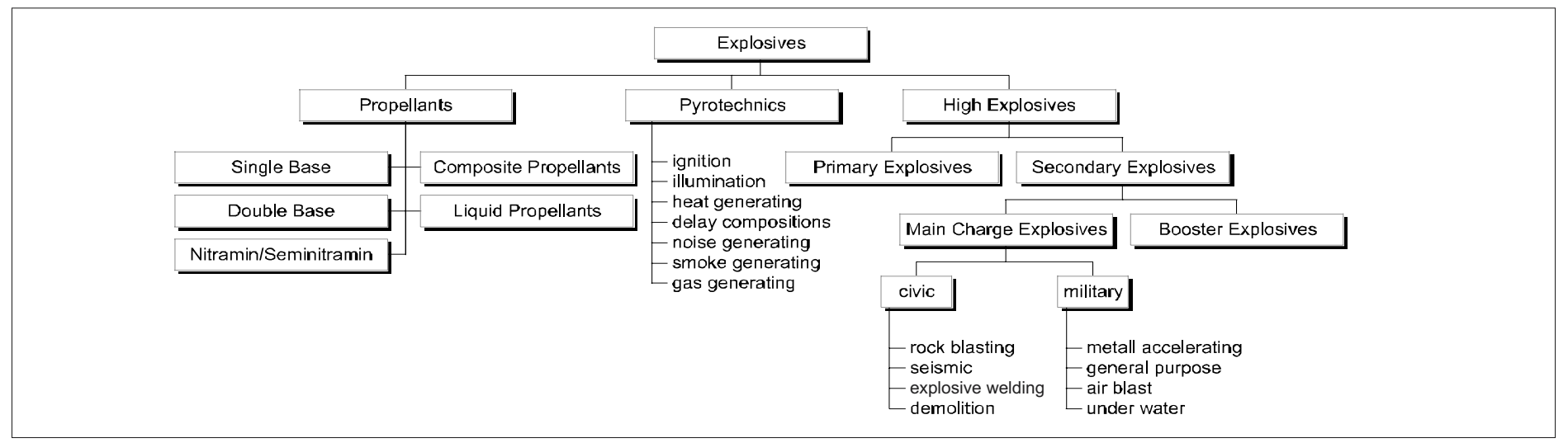

Fig. 1. Classification of explosives

charges which approach the theoretically maximum density. Due to this fact, many booster charges have lower densities.

\section{Chemistry and Application of Explosives}

Depending on their purpose, explosives are divided into three main types: high explosives, pyrotechnics, and propellants (Fig. 1). Whereas the output of high explosives is a detonation, propellants serve to accelerate either projectiles or missiles, and pyrotechnics produce some sort of fire. This production of fire is based on a redox reaction of inorganic reducing agents and oxidizer compounds.

For propellants, the chemistry of the compounds can be divided into three groups. There are the nitrocellulose-based ones, which are most widely used for gun applications. Single base, double base and semi-nitramine propellants belong to this group. In double-base propellants up to $40 \%$ of glycerine trinitrate is added. This way the energy output of such charges can be enhanced. In semi-nitramines the same effect is established by adding a crystalline nitramine compound, such as cyclo-1,3,5trimethylene-2,4,6-trinitramine (RDX), to the nitrocellulose matrix. A further group of propellants is based on a synthetic polymer binder system. This polymer binder can be either inert or energetic. If organic nitramine compounds are added to such a polymer, they form the base composition of nitramine propellants. When an inorganic salt is added as an oxidizer the formulation is called a composite propellant. Composite propellants are widely used for rocket propulsion. Finally there are the liquid propellants, which are mainly used in space exploration and technology. Liquid propellants are divided into mono- and bi-propellants. A typical mono-propellant is hydrazine, which burns in the absence of external oxygen. The fuel and oxidizer in bi-propellant systems are stored in separate tanks. Upon injection into a combustion chamber, they react and ignite. Kerosene or asymmetric dimethylhydrazine are often used as fuel. Typical oxidizers are nitric acid or dinitrogen tetroxide [11][17].

High explosives (Fig. 1) can be grouped into primary and secondary explosives. Primary explosives are most frequently based on heavy metal salts. They are used in low quantities in detonators to convert a certain input stimulus, such as fire, friction, impact or electricity, into a detonation. This detonation is taken up by booster explosives, which amplify the detonation and transmit it further to the main charge. Main charge explosives are responsible for the final effect. Traditional booster explosives are based on trinitro-2,4,6-phenylmethylnitramine (Tetryl), pressed TNT or PETN. More modern ones are based on RDX. Main charge explosives can be very different and their composition depends strongly on their application. High-performance metal accelerating applications are often based on cyclotetramethylene tetranitramine (HMX) and a binder system. The amount of binder can be as low as $5 \%$. On the other hand, blasting explosives can be very heterogeneous, for example ammonium nitrate (AN) is used as an oxidizer for a liquid fuel oil. Between these two extremes nearly every combination can be found [24].

\subsection{High Explosives}

The most frequently used primary explosives are lead azide, lead trinitroresorcinate, and tetrazolyl guanyltetrazene hydrate (tetracene). In earlier times also mercury fulminate was used. Lead azide has an excellent capability to initiate booster explosives, already at quantities below $0.1 \mathrm{~g}$. Lead azide is very sensitive to friction, lead trinitroresorcinate towards electrostatic discharge and tetracene to impact [10]. Quite often, corresponding mixtures are used to design a primary explosive for a certain input stimulus and a sufficient output performance. Common to most primary explosives is the presence of lead and the corresponding environmental impact when they are brought to function. Therefore lead-free primary explosives are sought. One example of these new substances for use in lead free priming compositions is 1,3,5-triazido2,4,6-trinitrobenzene (TATNB) [27]. Unfortunately, over a timeframe of years, TATNB undergoes a decomposition reaction which results in a loss of initiating power. Another approach to obtain leadfree primers was to substitute lead by another less toxic metal. Development work with silver azide or silver fulminate was undertaken. Both have a good initiation capability, but their sensitivity makes a commercial use impossible [10]. In spite of all these efforts to substitute lead in primary explosive compositions, a real breakthrough has not been realized up to now.

In the field of main charge explosives, especially in view of military applications, many new energetic molecules have been synthesized [14]. The main objective in high-performance applications is to put as much energy as possible into a minimum amount of space [28]. Based on computer simulations [24][29], high energy and at the same time high density explosive target molecules have been defined. In organic chemistry high densities can be achieved if the molecular structure contains fused ring systems. Energy can be brought into the system by strained ring systems and nitro or nitramine groups are responsible for an appropriate oxygen balance and nitrogen content. So, target molecules such as octanitrocubane or octaazacubane (Fig. 2) were defined. Octaazacubane was predicted to have a density of $2.69 \mathrm{gcm}^{-3}$ and a detonation velocity of about $15 \mathrm{kms}^{-1}$, far more than the most powerful high explosives known today [12][13][30]. Even if octanitrocubane has been synthesized in the meantime, cubane chemistry is too complicated to produce quantities for use in corresponding charges [31]. Another interesting cage structure, which can be synthesized quite easy, is based on the isowurtzitan structure (Fig. 3). There are two molecules representing this class of energetic high density substances: 2,4,6,8,10,12-(hexanitro-hexaaza)-tetracyclododecane (HNIW) 

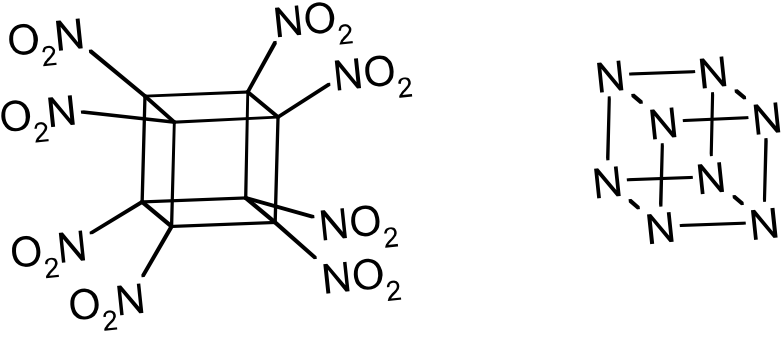

Fig. 2. High explosive molecules based on the structure of cubane uniform distribution, the homogeneity of corresponding high explosive compositions should be enhanced and also the detonation velocity should increase. None of these effects could be observed so far. Because nano particles tend to form agglomerates, it is not clear at the moment whether a less favorable ratio of aluminum to aluminum oxide for small particles or insufficient dispersion technology is responsible for the so far disappointing results.

\subsection{Propellants}

The nitration of nitrocellulose is a wellknown traditional process, which is not very exciting for most chemists [7]. The main development in the field of nitrocellulose based gun propellants can be identified in the application of new plasticizers, new surface-burning moderants and new crystalline nitramine compounds [17][40]. Environmental aspects have to be taken increasingly into account when new propellants are developed. Dinitrotoluene for example, which acts as coolant to reduce flame temperature, has to be substituted because its use was (or will be) forbidden in many countries. Lead- or tin-containing compounds used as burning rate modifiers have to be substituted also. The complete substitution of nitrocellulose was targeted when the first nitramine propellants were developed. The main problem with this sort of propellants is a completely different burning behavior and a lack of performance, especially if inert binder systems were used. Even if new energetic polymers and plasticizers are available today, for gun applications nitrocellulose will remain the first choice, because of its well-known favorable properties and its highly competitive price. In the area of solid rocket propellants, new energetic polymers and plasticizers are available in large scale [16]. Also energetic compounds with high gas production rate are entering in new development programs [41].

\subsubsection{Solid Gun Propellants}

Single-base propellants consist of $90 \%$ or more of nitrocellulose, which is gelled by adding a plasticizer. Quite frequently dibutyl phthalate is used for this purpose. It acts at the same time as a surface moderant and as a coolant [11]. Surface moderants and their diffusion characteristics are important factors for the design of the burning behavior of propellants. Especially their diffusion from the surface into the interior of the grain during the ageing process influences the ballistic stability significantly.

In double-base propellants glycerine trinitrate acts as an additional source of energy as well as a plasticizer. Small molecules such as dibutyl phthalate or camphor cannot be used as surface moderants in such propellants. Due to the plasticizing charac-
There is a second area of interest for chemists over the last two decades: insensitive, less powerful high explosive mole- are added [24]. First papers have been published about the use of nano-scaled aluminum particles [39]. Due to their more 
teristic of glycerine trinitrate, they migrate much too fast into the propellant grain and the surface effect is lost. Therefore oligomeric and polymeric surface moderants have been developed [42]. Normally double-base propellants are chemically less stable than single-based ones. This reduced stability can be detected by a faster consumption of stabilizers and a more pronounced heat flow generated by corresponding ageing reactions [43]. The shelf life of a double-base propellant is therefore normally shorter than that of a single-base propellant. Due to the higher energy content also the flame temperatures of a double-base propellant are higher.

High flame temperatures are an important factor influencing erosion effects in gun barrels [44] and should therefore be kept below a certain limit, which is for example about $3000 \mathrm{~K}$ for non chromiumplated medium caliber tubes [45]. Sometimes titanium dioxide or talc is used as a propellant ingredient to reduce barrel erosion. Often the surface of single- or doublebase propellants is treated with graphite. This treatment improves the flow characteristics of the grains and results in a higher loading density. Furthermore graphite avoids electrostatic charging. Finally decoppering agents and muzzle flash inhibitors can belong to a classical single- or double-base propellant composition. Typical muzzle flash inhibitors are potassium nitrate or sulphate as well as sodium oxalate [11]. In semi-nitramine propellants most frequently RDX is added to the nitrocellulose matrix. The main problems encountered with these propellants are again very high flame temperatures with corresponding barrel erosion problems. On the other hand, the so-called LOVA propellants, which are based on a nitramine and an inert binder system, do not contain enough energy to fulfill the performance requirements for most modern applications. Maybe new energetic polymers and corresponding plasticizers, which are also under development for solid rocket propellant applications, will solve this problem in future.

\subsubsection{Solid Rocket Propellants}

Solid rocket propellants are either of the type of double base, elastomer modified double base (EMDB) or composite. Composite propellants consist of a binder system that acts as a fuel, a crystalline oxidizer and further additives, such as bonding agents or burn rate catalysts. The classical and most commonly used oxidizers are ammonium perchlorate (AP) and ammonium nitrate (AN). During the burning process of an AP-based rocket motor a lot of hydrochloric acid is developed. Together with the moisture of the air it forms a white smoke, so that the trajectory and also the starting point of the missile can easily be

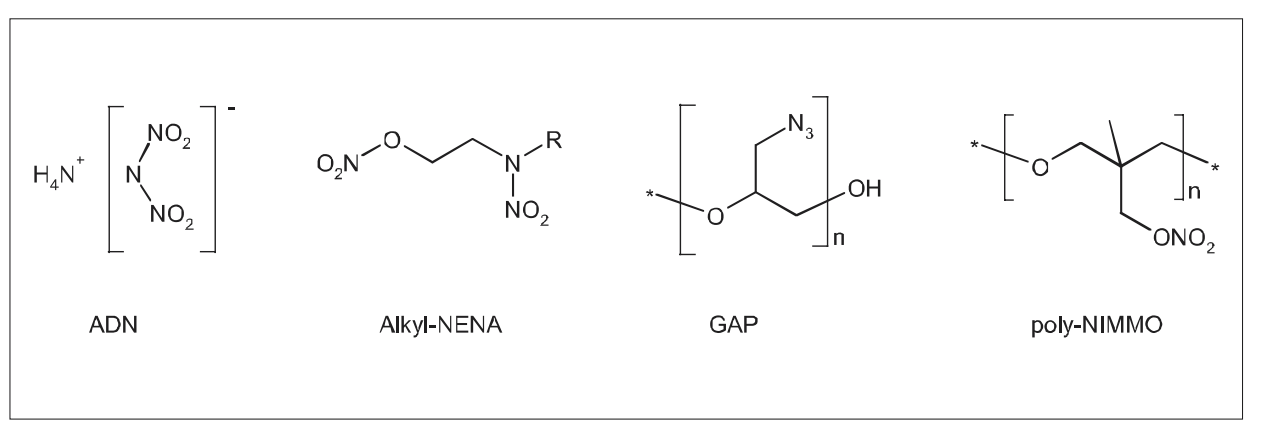

Fig. 5. Modern ingredients for solid rocket propulsion

observed. Therefore in some solid rocket propellant compositions an $\mathrm{HCl}$-suppressant is added. The most commonly used ingredients for this purpose are magnesiumaluminum alloys [46] or sodium nitrate [11]. AN on the other hand does not show the problem of $\mathrm{HCl}$ production. But the main drawback in the use of AN for rocket propulsion is its conversion into different crystal modifications already at low temperatures. Therefore AN has to be phasestabilized with potassium nitrate.

A new and very powerful compound for solid rocket motors is ammonium dinitramide (ADN). Originally developed in the former Soviet Union, ADN has become a key ingredient in research for rocket propulsion all over the world. ADN has a positive oxygen balance $(+25.8 \%)$, a high nitrogen content $(45.1 \%)$ and a high enthalpy of formation. Its sensitivity towards friction or impact remains reasonable [10]. Also other nitramines, such as RDX, HMX and HNIW are used in rocket motors formulations. In contrast to their use in high explosives, the content in rocket motors is in the range of about $60 \%(\mathrm{w} / \mathrm{w})$ only. To guarantee a uniform burning process, ground material with a medium particle size of a few microns, in combination with corresponding bonding agents and burn rate catalysts, are used [17][47]. In classical composite rocket motors, inert hydroxyterminated poly-butadienes (HTPB) or polyesters are used as binder prepolymers. Using diisocyanates, these binders are cured to polyurethanes after the motor has been cast. A typical plasticizer for these types of polymers, such as di-(2-ethylhexyl) adipate (DOA) helps to design the final mechanical properties, especially at low temperatures.

Due to this high amount of inert material in classical composite propellants, investigations have been started for the synthesis of energetic polymers and energetic plasticizers. Today a whole series of energetic plasticizers are available in large scale [16] To decrease the freezing point and finally also the glass transition point of the polymer, where these plasticizers are applied also, quite frequently eutectic mixtures are used. This is the case if the ethyl and methyl derivative of N-alkyl-N-(2-nitroxyethyl)nitramine (alkyl-NENA) [48] or the mixture of bis-(2,2-dinitropropyl)acetale and bis(2,2-dinitropropyl)formal (BDNPAF) [49] are used as plasticizers (Fig. 5). The main problem in the application of plasticizers is the migration stability in the binder polymer. Therefore some chemical similarities are needed to avoid separation of polymer and plasticizers. Sometimes oligomers of the same base type as the binder polymer are added to obtain a plasticizer effect. This approach was chosen for the energetic polymers poly-3-nitratomethyl-3-methyloxethane (poly-NIMMO) and glycidyl azide polymer (GAP) [50]. On the other hand butyl-NENA shows also a good migration stability in a poly-NIMMO matrix [51].

There are many other new energetic polymers under development. Some of them are very promising, especially because it seems to be possible to combine a high energy content with well-designed mechanical properties. This design is based on hard and soft block polymer elements, which tend to form crystallite structures or random coils respectively. The number and the sequence of these hard and soft block elements define the mechanical properties of the polymer [52].

\subsection{Pyrotechnics}

Most pyrotechnic compositions are based on reducing agents, also called fuels, oxidizer components, binders and further ingredients to generate certain effects. The understanding of a pyrotechnic reaction can sometimes be very difficult, because in solid-state reaction chemistry many factors, such as particle size, impurities and oxidation layers on the surface of fuels can influence the reaction behavior significantly. In many cases when the manufacturer of a pyrotechnic compound was changed, also the pyrotechnic composition had to be adjusted. So many pyrotechnic compositions up to now are based on trial and error or, more scientifically, have an empirical background. This is the main reason why only a few common compositions exist, which are used exactly the same way all over the world. In military as well as in civic pyrotechnics, the generation of effects has 
been published in a general way, but the details for a certain application have to be adjusted from case to case.

Pyrotechnic effects can be generation of heat, hot particles or a flame, generation of gas or smoke, generation of light in different colors, generation of noise, such as a loud bang or a whistling sound. Furthermore, very slowly reacting pyrotechnic compositions are used to delay an initiation train, e.g. in a hand grenade.

Generation of hot particles can be used for ignition of propellants. In many traditional applications black powder was used for this purpose [11]. In rocket propulsion boron/potassium nitrate is used quite frequently.

Generation of heat and light is the basic concept of flares, which serve for the protection of aircrafts towards hostile missiles attacks. Traditional flares are based on Magnesium Teflon and Viton (MTV) compositions. To overcome new sensor technologies, modern flare compositions try to imitate the emission spectrum of a jet plume [53].

Many smoke-generating compositions not only act in the visible area of the electromagnetic spectrum, but also in the infrared range [54]. Traditional smoke generators are based either on red phosphorus and corresponding oxidizers or zinc, hexachloroethane, aluminum mixtures.

Light-generating compositions are used in tracers, for illumination, but also for art fireworks. Many of them contain nitrates and perchlorates as oxidizers and alkaline earth metals, magnesium, aluminum, zirconium and titanium as fuels [11]. To produce a light of a certain color, they contain some metal compounds that produce spectral emissions at characteristic frequencies. So red light is produced if a strontium salt is added to a pyrotechnic system. Corresponding mixtures of perchlorates with a sodium salt gives a yellow, with a barium salt a green and with a copper (II) salt a blue light [55]. In these reactions the decomposition of perchlorate and the formation of excited metal chloride cations play the key role in light emission.

Loud bangs are produced by gas-generating pyrotechnic mixtures filled in a sealed cardboard tube. After ignition a lot of gas is produced that eventually bursts the tube resulting in a big bang. Quite frequently black powder is used for this purpose [11].

Other gas generators are needed for air bags in car safety systems. In this case sodium azide, which develops nitrogen in large quantities when heated up with a corresponding ignition charge, is used.

Delay mixtures on the other hand contain frequently zirconium or nickel as a fuel and lead oxide, barium chromate or potassium perchlorate as oxidizers. In case of chromates no or only low quantities of gases are produced during the reaction.
In the future pyrotechnics will make an important step forward by applying the possibilities of nano technology. A series of metal powders in nano scale is available today, but some have a highly pyrophoric characteristic. On the other hand also some oxidizers can be produced as nano powders. By means of sol-gel chemistry fuels and oxidizers can be put together to mixtures with homogeneities that were not achievable before [19].

\section{Conclusions}

People working with explosives are said to be conservative with respect to the use of new energetic compounds. Many old traditional explosives, such as black powder, nitrocellulose or TNT are still in use today. Nevertheless, new energetic material has been developed and introduced in modern applications.

In the field of high explosives, high density and high energy compounds based on fused ring systems or even cages are available. But a real breakthrough, where detonation velocities in a new order of magnitude become true, has not been achieved. As long as traditional organic nitration chemistry is the basis for the synthesis of new energetic molecules, this situation will not change. Maybe there will be a potential in nitrogen cage chemistry or in silicon nano technology [56].

Big steps forward were made in the field of intrinsically less sensitive, less powerful high energetic molecules. Some new substances have already been introduced into applications or are on the way to it. This new energetic material is one of the main factors in the improvement of safety in corresponding applications.

In the area of propellants, especially for guns, nitrocellulose will remain the key ingredient, also in future. There are new energetic polymers in discussion, but at the moment it is doubtful whether they can ever be produced for a competitive price.

In the field of solid rocket propellants a development of new energetic binder systems and new high performance fuels can be observed. Especially ADN, HNIW and GAP have to be mentioned in this context. The application of these new ingredients will enhance the performance and minimize the signature of solid rocket propulsion significantly.

In pyrotechnics the development of spectral flares to mislead modern missile sensors, IR tight smokes or compositions with illumination capability in the infra red range is of high interest.

The future will show the impact of nano technology on pyrotechnic applications. Today, even if the consequences cannot be predicted in detail, a great potential for new explosives with new properties is expected to become reality.

Received: March 30, 2004

[1] 'Manual of Data Requirements and Tests for the Qualification of Explosive Materials for Military Use', Allied Ordnance Publication Nr. 7, second edition, North Atlantic Treaty Organization, Brussels, 2003.

[2] 'Recommendations on the Transport of Dangerous Goods, Manual of Tests and Criteria', third revised edition, United Nations, New York and Geneva, 1999.

[3] a) Bundesgesetz über explosionsgefährliche Stoffe (Sprengstoffgesetz), 941.41, Bern, 1977; Verordnung über explosionsgefährliche Stoffe (Sprengstoffverordnung, SprstV), 941.411, Bern, 2000; Gesetz über explosionsgefährliche Stoffe (Sprengstoffgesetz, SprengG), Berlin, BGBI I S. 3970, 2002; Erste Verordnung zum Sprengstoffgesetz (1. SpengV), Berlin, BGBI I S. 4013, 2002.

[4] P.W. Cooper, 'Explosives Engineering', Wiley-VCH, New York, 1997.

[5] G.F. Kinney, K.J. Graham, 'Explosive Shocks in Air', Springer-Verlag, New York, 1985.

[6] S. Fordham, 'High Explosives and Propellants', Pergamon Press, Oxford, 1980.

[7] T. Urbański, 'Chemistry and Technology of Explosives', Pergamon Press, Oxford, 1986.

[8] P.R. Lee, in 'Explosive Effects and Applications', Ed. J.A. Zukas, W.P. Walters, Springer-Verlag, New York, 1997, p. 23.

[9] A. Bailey, S.G. Murray, 'Explosives, Propellants \& Pyrotechnics', Brassey's, London, 2000.

[10] R. Meyer, J. Köhler, A. Homburg, 'Explosives', Wiley-VCH, Weinheim, 2002.

[11] J. Akhavan, 'The Chemistry of Explosives', RSC Paperbacks, Cambridge, 1998.

[12] J.C. Oxley in 'Explosive Effects and Applications', Ed. J.A. Zukas, W.P. Walters, Springer-Verlag, New York, 1997, p. 137.

[13] N.C. Paul in 'Explosives in the Service of Man', Ed. J.E. Dolan, S.S. Langer, The Royal Society of Chemistry, Cambridge. 1997.

[14] P.F. Pagoria, G.S. Lee, A.R. Mitchell, R.D. Schmidt, Thermochim. Acta 2002, 384, 187.

[15] G.P. Sollott, J. Alster, E.E. Gilbert, O. Sandus, N. Slagg, J. Energ. Mater. 1986, 4, 5; J. Boileau, J.-M. L. Emeury, J.-P. Kehren, 'Tetranitroglycoluril and method of preparation thereof', United States Patent 4,487,938, 1984; A.T. Nielsen, 'Caged Polynitramin Compound', United States Patent 5,693,794, 1997.

[16] A. Provatas, 'Energetic Polymers and Plasticisers for Explosive Formulations A review of recent advances', DSTO Technical Report Nr. TR-0966, 2000. 
[17] N. Kubota, J. Pyrotechnics 2000, 11, 25.

[18] M.W. Smith, M.D. Cliff, J. Energ. Mater. 1999, 17, 69; B. Berger, P. Folly, G. Wilfing, R. Kresse, 'New Oxidizer for Special Applications in Pyrotechnics', 32 ${ }^{\text {nd }}$ Int. Annual Conf. of ICT, Karlsruhe, Germany, 2001, V1.

[19] R.L. Simpson, T. Tillotson, L. Hrubesh, A Gash, 'Nanostructurated energetic materials derived from sol-gel chemistry', $31^{\text {st }}$ Int. Annual Conf. of ICT, Karlsruhe, Germany, 2000, V35.

[20] D. Desailly, Y. Guengant, P. Brunet, B. Briquet, D. Houdusse, J. Tersac, 'Numerical simulation of reaction violence to cook-off experiments', Insens. Mun. \& Energ. Mater. Symp. 2003, Orlando, USA.

[21] U. Ticmanis, S. Wilker, G. Pantel, M. Kaiser, P. Guillaume, C. Bales, N. van der Meer, 'Principles of a STANAG for the estimation of the chemical stability of propellants by heat flow calorimetry', $31^{\text {st }}$ Int. Annual Conf. of ICT, Karlsruhe, Germany, 2000, V2.

[22] H. Andres, B. Vogelsanger, 'Problematik der N-Nitrosamine in Treibladungspulvern' (NITROCHEMIE AG), SIG BP 2858, 2003.

[23] B. Vogelsanger, R. Soppraneti, 'Sicherheits-, Stabilitäts- und Lebensdaueruntersuchungen im Lebenszyklus von Treibladungspulvern', Workshop Mikrokalorimetie \& Thermoanalyse, WIWEB, Swisttal, Germany, September 13, 1995.

[24] E. Anderson, Prog. Astronaut. Aeronaut. 1993, $155,81$.

[25] H. Bircher, J. Mathieu, P. Mäder, B. Berger, 'CL-20 based formulations for high performance warhead applications', Insens. Mun. \& Energ. Mater. Symp. 1999, Orlando, USA.

[26] 'Explosives, Shock Sensitivity', Standard Agreement of NATO governments (STANAG), Nr. 4488, North Atlantic Treaty Organisation, Brussels, 2001.

[27] D. Adam, K. Karaghiosoff, M. Klapötke, G. Holl, M. Kaiser, Propellants, Explos. Pyrotech. 2002, 27, 7.

[28] J.P. Agrawal, Prog. Energy Combust. Sci. 1998, 24, 1.

[29] P.B. Kempa, J. Kerth, 'WinMOPAC - A helpful Tool for the Simulation of New Energetic Molecules', 32 ${ }^{\text {nd }}$ Int. Annual Conf. of ICT, Karlsruhe, Germany, 2001, P147; Y. Akutsu, R. Che, M. Tamura, J. Energ. Mater. 1993, 11, 173; M.J. Kamlet, H. Hurwitz, J. Chem. Phys. 1968, 23, 3685; L.R. Rothstein, R. Peterson, Propellants, Explos. Pyrotech. 1979, 4, 56.

[30] J.R. Stine, Mat. Res. Soc. Symp. 1993, 296, 3.

[31] P.E. Eaton, M.X. Zhang, Propellants, Explos. Pyrotech. 2002, 27, 1.

[32] J. Hanks, T. Highsmith, A. Sanderson, K. Warner, J. Worthington, 'The Development of a Scalable Route to TEX $(4,10$ dinitro-2,6,8,12-tetraoxa-4,10-diazatetracyclo $\left[5 \cdot 5 \cdot 0.0^{5,9} 0^{3,11}\right]$-dodecane)', $33^{\text {rd }}$
Int. Annual Conf. of ICT, Karlsruhe, Germany, 2002, P129.

[33] K. Dudek, M. Rajic, Z. Zeman, M. Suceska, P. Vavra, J. Energ. Mater. 2001, 19 , 219; M.D. Coburn, M.A. Hiskey, T.G. Archibald, Waste Manage. 1997, 17, 143; K. Schmid, D. Kaschmieder, 'Synthesis and properties of TNAZ', $31^{\text {st }}$ Int. Annual Conf. of ICT, Karlsruhe, Germany, 2000, V10.

[34] R.D. Schmidt, A.R. Titchell, G.S. Lee, M.D. Coburn, P.F. Pagoria, W.T. Quinlan, R. Thorpe, M. Cates, 'New synthesis of TATB - Scaleup and product characterization', $31^{\text {st }}$ Int. Annual Conf. of ICT, Karlsruhe, Germany, 2000, V37.

[35] N.V. Latypov, J. Bergman, A. Langlet, U. Wellmar, U. Bemm, Tetrahedron 1998, 54 , 11525; H. Östmark, H. Bergman, U. Bemm, P. Goede, E. Holgrem, M. Johannson, A. Langlet, N.V. Latypov, A. Pettersson, M.-L. Pettersson, N. Wingborg, C. Vörde, H. Stenmark, L. Karlsson, M. Hihkiö, '2,2-Dinitro-ethene-1,1-diamine (FOX-7) - Properties, Analysis and Scale-up', $32^{\text {nd }}$ Int. Annual Conf. of ICT, Karlsruhe, Germany, 2001, V26.

[36] A.R. Basal, V.L. Zbarsky, V.F. Zhilin, 'About some Features of Synthesis NTO', $32^{\text {nd }}$ Int. Annual Conf. of ICT, Karlsruhe, Germany, 2001, P73.

[37] A. Becuwe, A. Delclos, Propellants, Explos. Pyrotech. 1993, 18, 1.

[38] J. Kerth, W. Kuglstatter, 'Synthesis and Characterization of 2,6-Diamino-3,5Dinitropyrazine-1-Oxide (NPEX-1)', $32^{\text {nd }}$ Int. Annual Conf. of ICT, Karlsruhe, Germany, 2001, P166; T.D. Tran, P.F. Pegoria, D.M. Hoffman, J.L. Cutting, R.S. Lee, R.L. Simpson, 'Characterization of 2,6Diamino-3,5-Dinitropyrazine-1-Oxide (LLM-105) as an Insensitive High Explosive Material', 33 ${ }^{\text {rd }}$ Int. Annual Conf. of ICT, Karlsruhe, Germany, 2002, V45.

[39] P. Brousseau, M.D. Cliff, 'The Effect of Ultrafine Aluminum Powder on the Detonation Properties of Various Explosives', $32^{\text {nd }}$ Int. Annual Conf. of ICT, Karlsruhe, Germany, 2001, V37; A. Lefrancois, C. Le Gallic, 'Expertise of Nanometric Aluminum Powder on the Detonation Efficiency of Explosives', 32 ${ }^{\text {nd }}$ Int. Annual Conf. of ICT, Karlsruhe, Germany, 2001, V36.

[40] R. Simmons, 'New energetic propellants for hypervelocity applications: A challenge to the synthesis chemist', $31^{\text {st }}$ Int. Annual Conf. of ICT, Karlsruhe, Germany, 2000, P49.

[41] J.C. Bottaro, P.E. Penwell, R.J. Schmitt, J. Am. Chem. Soc. 1997, 119, 9405.

[42] B. Vogelsanger, B. Ossola, 'Benchmarking von Phlegmatisatoren - Vergleich der Diffusionsgeschwindigkeiten verschiedener Phlegmatisatoren in einer Referenz-Treibladungspulver-Matrix' (NITROCHEMIE AG), SIG BP 2759, 2001.

[43] 'Explosives, Nitrocellulose Based Propellants containing Nitroglycerine and Stabi- lized with Diphenylamine, Stability Test Procedures and Requirements', Standard Agreement of NATO governments (STANAG), Nr. 4541, Ed.1, North Atlantic Treaty Organisation, Brussels, 2000.

[44] N. Desgardin, C. Perut, 'Additives for Gun Propellants to Increase Impetus and Decrease Erosion', 33rd. Int. Annual Conf. of ICT, Karlsruhe, Germany, 2002, V20.

[45] B. Vogelsanger, S. De Boni, 'Nächste Generation Mittelkaliber-Treibladungspulver' (NITROCHEMIE AG), SIG BP2685, 1998.

[46] H. Habu, K. Hori, T. Saito, M. Kohno, 'The Combustion Mechanism of AP Based Propellant Containing Magnalium', 32nd. Int. Annual Conf. of ICT, Karlsruhe, Germany, 2001, V7.

[47] P.G. Shrotri, H. Singh, S.N. Asthana, M.V. Vaida, J. Energ. Mater. 1992, 10, 1; V. Weiser, N. Eisenreich, W. Eckl, S. Eisele, M. Menke, 'Burning Behaviour of CL20/GAP and HMX/GAP-propellants', $31^{\text {st }}$ Int. Annual Conf. of ICT, Karlsruhe, Germany, 2000, P144; V.A. Babuk, V.A. Vassiliev, D.B. Molostov, 'Solid Rocket Propellants on the Basis of Ammonium Dinitramide - Problems and Perspective Applications', 33 ${ }^{\text {rd }}$ Int. Annual Conf. of ICT, Karlsruhe, Germany, 2002, V21.

[48] G.F. White, W.J. Chute, 'Method of Converting Secondary Amines to Nitramines', United States Patent 2,462,052, 1949.

[49] B.R. Wardle, S. Hamilton, M. Geslin, V. Mancini, D. Merrill, 'An Environmentally Favorable Continuous Process for the Synthesis of BDNPA/F', $30^{\text {th }}$ Int. Annual Conf. of ICT, Karlsruhe, Germany, 1999, V39.

[50] M.E. Colclough, N. Chauhan, A.V. Cunliffe, 'New Energetic Plastizisers', Insens. Mun. \& Energ. Mater. Symp. 1997, Tampa, USA

[51] P. Flower, B. Garaty, 'Characterization of PolyNIMMO and PolyGLYN Energetic Binders', $25^{\text {th }}$ Int. Annual Conf. of ICT, Karlsruhe, Germany, 1994, 70-1.

[52] J. Hamid, R.M. Endsor, 'Recent Advances in Energetic Binder Synthesis', Insens. Mun. \& Energ. Mater. Symp. 2003, Orlando, USA.

[53] E.-C. Koch, Propellants, Explos. Pyrotech. 2001, 26, 3.

[54] C. Hug, J. Grundler, 'The self-protection smoke system Maske with combined efficacy in the visible and infrared sections of the electromagnetic spectrum', 26 $6^{\text {th }}$ Int. Annual Conf. of ICT, Karlsruhe, Germany, 1995, 10-1.

[55] B.V. Ingram, J. of Pyrotechnics 2003, 17, 1.

[56] J. Diener, E. Gross, N. Künzner, D. Kovalev, V. Timosnenko, M. Schildknecht, K. Rudolf, H. Hofmann, 'Nanostrukturierte Reativstoffe', EP 1334955 A2, Patentblatt 2003/33, Europäisches Patentamt, 2003. 